\title{
Productivity Analysis of Front-end Loader in Timber Harvesting*
}

\author{
Abdullah E. Akay ${ }^{(D)}$, Ebru Bilici² ${ }^{(D)}$, Inanç Tas ${ }^{1 * *(D)}$, H. Eren Findik ${ }^{1(D)}$ \\ ${ }^{1}$ Bursa Technical University, Faculty of Forestry, 16310, Bursa, Turkey \\ ${ }^{2}$ Giresun University, Dereli Vocational School, Giresun, Turkey
}

\begin{abstract}
In this study, the productivity of front-end loader (Liebherr L 514 Stereo), which is one of the most used mechanized harvesting equipment in the production of forest products, was analyzed using time-study method. Factors influencing loader productivity were also evaluated by statistical analysis. Time measurements were carried out during forest harvesting operations in Topçam Forest Enterprise Chief in the city of Giresun. The results indicated that the most time-consuming stage of the loading operation was moving loaded to the logging truck, followed by moving unloaded to the side of the logs. According to the results, the average productivity of the loader was $34.27 \mathrm{~m}^{3} / \mathrm{hr}$. Correlation test results showed that there was a positive correlation between productivity and $\log$ diameter and log volume, while there was no significant relationship between productivity and log length. The regression model developed with respect to the loader's productivity and specified log parameters (i.e. $\log$ diameter and log volume) was found to be significant and adequately explained the productivity of the loader. It was found that there was a significant relation between loader productivity and diameter classes and volume classes. It was also found that loader productivity increased as log diameter and log volume increases.
\end{abstract}

Keywords: Forest harvesting, mechanized loading, front-end loader, productivity

\section{Introduction}

The increasing demand of the population and society has increased the pressure on natural resources, thus the products and services provided from the forests should be planned effectively and continuously. For this reason, the forests which are among the top natural resources should be planned considering the optimum efficiency, minimum environmental impact, and economic factors (Kovacsova and Antalova, 2010). Considering that the need of the society, especially for wood-based forest products, will increase gradually, it is foreseen that the inclusion of modern techniques and technological tools and equipment in the work of forest harvesting will be of increasing importance.

Production stages of wood-based forest products include felling, delimbing, debarking, bucking, timber extracting, loading, hauling, unloading and stacking (Eker and Acar, 2006). These stages are implemented with different applications which are developed to reduce costs, simplify the work and ensure the time efficiently (Coskun et al., 2010). When modern techniques and technological tools are not put into practice, they are improperly planned or applied, production stages can be not economic, take much longer than usual, damage the residual stand and forest soil, and reduce quality of the product (Acar and Senturk, 2000; Akay et al., 2007; Eroglu, 2012). Loading, which is one of the production stages, is of great importance in transporting the products reaching from the forests to the landing without losing time. The efficiency of this stage depends on the harmony of planning of its sub-phases.

In this study, it was aimed to investigate the performance of mechanical loading operation in mountainous terrain based on hourly productivity. In this context, precision forestry tools were utilized in the data collection and data analysis stages. The hourly productivity of loading operation carried out using the Liebherr L514 Stereo loader was investigated by using the time study during loading of a logging truck (MercedesBenz AXOR 3240). In addition, the factors affecting the productivity (diameter, length, volume) were analyzed using statistical methods. The study was carried out in Mesudiye Forest Enterprise Directorate (FED) in the city of Ordu in Turkey. The slope of the terrain (almost flat) in the landing area and the number of pieces (mostly one log a time) were not taken into account as they did not vary in the field study.

\footnotetext{
${ }^{*}$ This work has been partially presented in FETEC2019 Symposium

**Corresponding author: Tel: +90 5300985835 E-mail: inanc.tas@btu.edu.tr 


\section{Material and Methods}

\subsection{Study Area}

The study area is located within the boundaries of Topçam Forest Enterprise Chief (FEC) in Mesudiye FED in Giresun Forest Regional Directorate (FRD) (Figure 1, 2). The dominant tree species in the study area are Eastern
Spruce (Picea orientalis) and Eastern Beech (Fagus orientalis). In this study, the loading of East Spruce logs, extracted from the forest compartments 137 and 138 in Topcam FEC, on the log truck located on the landing was examined.

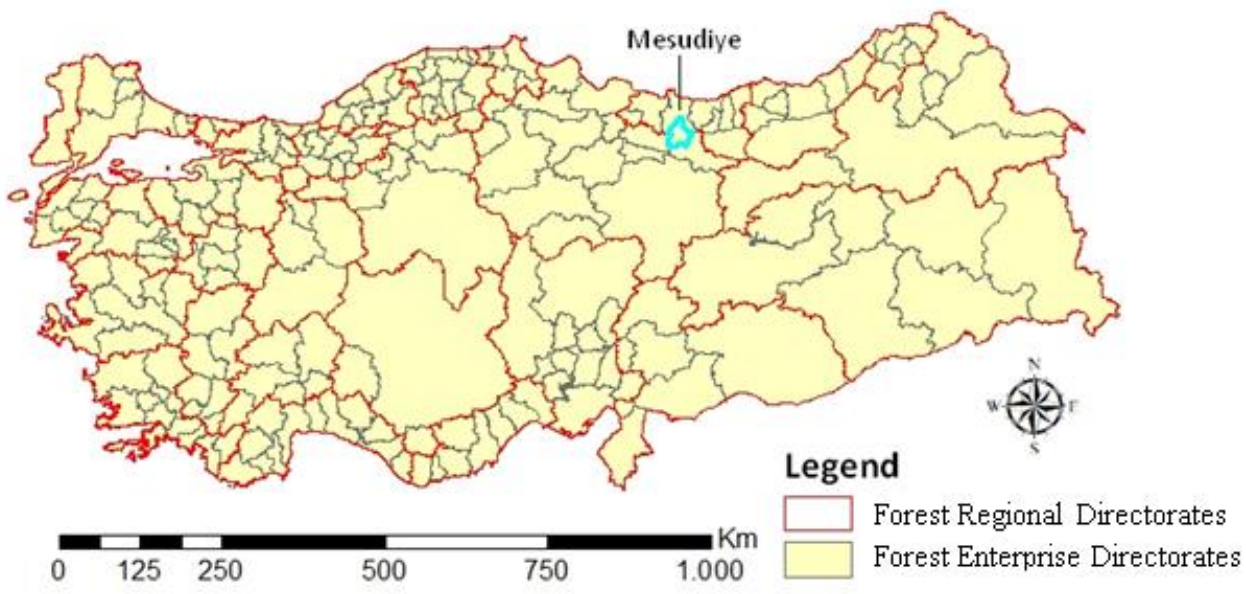

Figure 1. The location of Mesudiye on the map of Turkey

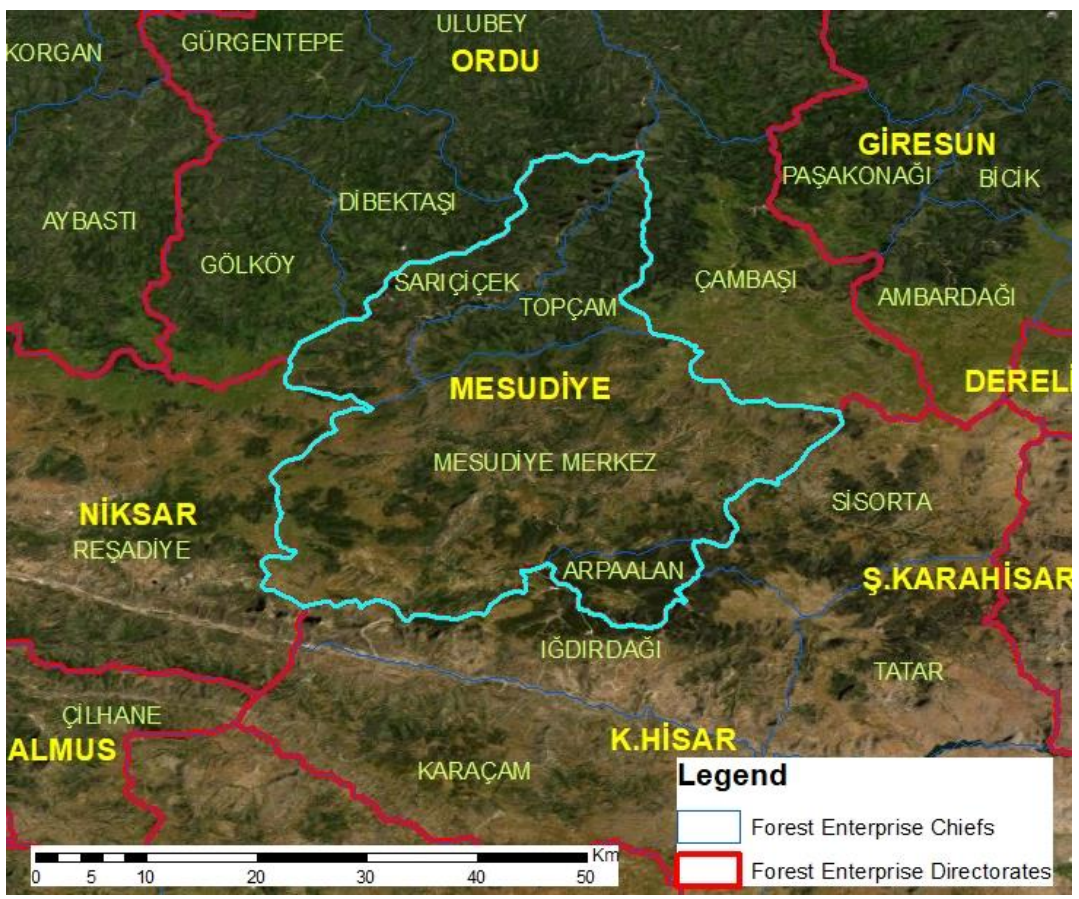

Figure 2. The location of theTopçam FEC

\subsection{Time Study}

In this study, the productivity of a front-end loader (Liebherr L514 Stereo), a common loader used in the loading wood-based products to the logging truck, was analysed by using time study method (Figure 3 ). During the loading operation, a total of two people were employed; one loader operator and one worker doing the product stacking in the truck. Two Selex 7064 chronometer was used during time measurement in the field. The average diameters and lengths of the logs were measured with the help of MANTAX
Precision Meter and Weiss brand tape, respectively. Before starting field surveys, a time study form was developed to record time measurements for each work stage in the loading study (Table 1). The work stages evaluated in the loading operation are; loader moving to logs on the ground, loading the logs by grapples, moving to logging truck, and unloading logs to the truck. In addition, the delay time (mechanical and personnelinduced delays) during the study was also recorded. 


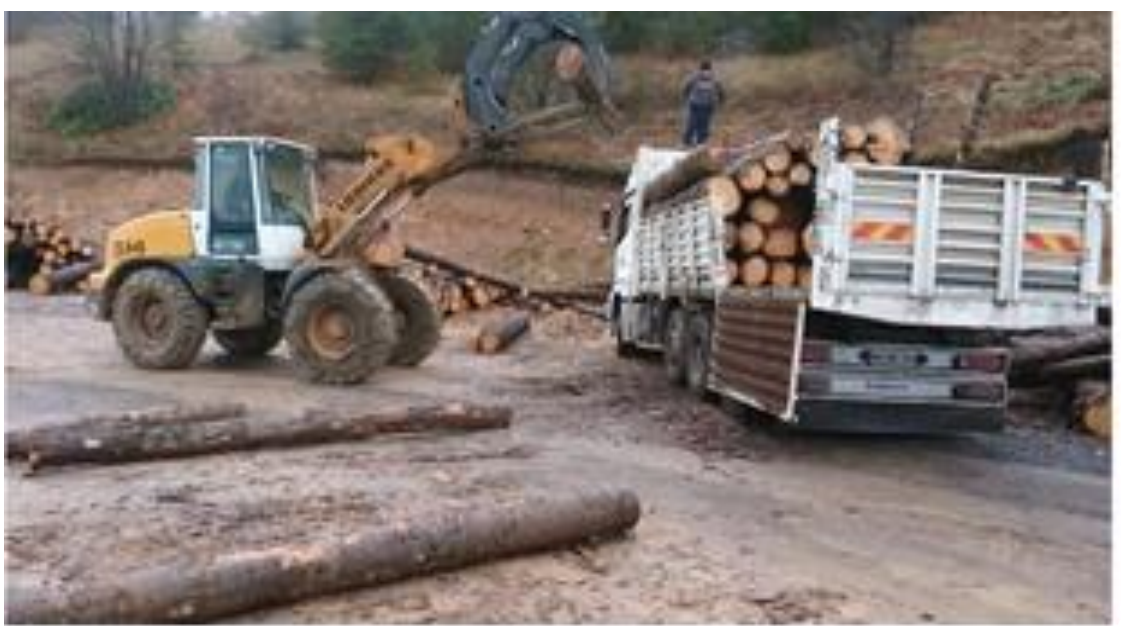

Figure 3. Loading operation

Table 1. Time study form

\begin{tabular}{|c|c|c|c|c|c|c|c|c|c|c|c|}
\hline \multicolumn{2}{|l|}{ Date: } & \multicolumn{3}{|l|}{ Truck Model: } & \multicolumn{7}{|c|}{ Weather: } \\
\hline \multicolumn{2}{|l|}{ FED } & \multicolumn{3}{|l|}{ Loading Model: } & \multicolumn{7}{|c|}{ Altitude and Aspect: } \\
\hline \multicolumn{2}{|l|}{ FEC: } & \multicolumn{3}{|l|}{ Truck capacity: } & \multicolumn{7}{|c|}{ Slope $(\%)$ : } \\
\hline \multicolumn{2}{|c|}{ Compartment number: } & \multicolumn{3}{|l|}{ Loading capacity: } & \multicolumn{7}{|c|}{ Workers: } \\
\hline & & & 1 & 2 & 3 & 4 & 5 & 6 & 7 & 8 & 9 \\
\hline \multirow{2}{*}{ Key Factors } & \multicolumn{2}{|c|}{ Diameter $(\mathrm{cm})$} & & & & & & & & & \\
\hline & \multicolumn{2}{|c|}{ Height $(\mathrm{m})$} & & & & & & & & & \\
\hline \multirow{4}{*}{ Stages } & \multicolumn{2}{|c|}{ Loader moves to logs on the ground } & & & & & & & & & \\
\hline & \multicolumn{2}{|c|}{ Loading the logs by the loader } & & & & & & & & & \\
\hline & \multicolumn{2}{|c|}{ Loader moves to logging truck } & & & & & & & & & \\
\hline & \multicolumn{2}{|c|}{ Loader Unloads logs the Truck } & & & & & & & & & \\
\hline Others & \multicolumn{2}{|c|}{ Delay time } & & & & & & & & & \\
\hline
\end{tabular}

\subsection{Productivity Analysis}

By using the total time obtained by time measurement, the hourly productivity $\left(\mathrm{m}^{3} / \mathrm{h}\right)$ of the loading was determined. The following formula was used in productivity $(\mathrm{P})$ calculation:

$P=(V / t) 60$

$\mathrm{V}=$ Average product volume in a cycle $\left(\mathrm{m}^{3}\right)$

$\mathrm{t}=$ Average total time in one cycle $(\mathrm{min})$

$60=$ Coefficient used to convert time from minute to hour

One of the commonly preferred formulas in technical forestry applications, the Huber Formula, was used to calculate the volumes of products. In this formula, the product volume in each cycle was calculated based on medium log diameter (d) and length (L) (Carus, 2002):

$V=\pi d^{2} L / 40000$

$\mathrm{di}=$ Medium diameter of the product $(\mathrm{cm})$

$\mathrm{L}=$ Product length $(\mathrm{m})$

\subsection{Statistical analysis}

Within the scope of statistical analyzes; firstly, the duration of the work stages, product dimensions (diameter, length, volume) and the basic statistical values (average, maximum, minimum and standard deviation) of hourly productivity were determined. The Pearson Correlation Test was used to investigate the relationships between the variables (diameter, length, volume) and the variables and productivity. Then, taking into account the correlation test results, Linear

Regression Analysis was used to develop a mathematical model for dependent variable (productivity) depending on independent variables (diameter, length, volume). In order to examine the effect of $\log$ diameters and volumes on productivity, the logs were classified into three diameters (small: $<30 \mathrm{~cm}$, medium: $30-39 \mathrm{~cm}$ and large: $\geq 39 \mathrm{~cm}$ ) and three volume classes (low: $<0.30 \mathrm{~m}^{3}$, medium: $0.30-0.49 \mathrm{~m}^{3}$ and high: $\left.\geq 0.49 \mathrm{~m}^{3}\right)$. One-way ANOVA (0.05) was used to evaluate the relationship between diameter and volume classes and productivity. 


\section{Results and Discussion}

\subsection{Basic Statistical Results}

The basic statistical values (average, maximum, minimum and standard deviation) obtained for the variables (diameter, length, volume) related to the product dimensions affecting the productivity in the loading operation are given in Table 2 . The average log diameter, length and volume were determined as 34.07 $\mathrm{cm}, 3.90 \mathrm{~m}$ and $0.38 \mathrm{~m}^{3}$, respectively.

The basic statistical values (mean, max, min and standard deviation) of the time measurements of the work stages, delay time and loader productivity are given in Table 3. According to the results, it was found that the most time consuming stage in a loading cycle was the time for the loader to move to the truck $(31.15 \%)$, followed by the time for the loader to move to the $\log$ on the ground $(30.52 \%)$. When the mechanical and personnel delays are taken into consideration, it was determined that the delay time constitutes $25.29 \%$ of the total cycle time

Table 2. Basic statistical findings of the variables affecting the loading productivity

\begin{tabular}{cccccc}
\hline Variables & Unit & Average & Minimum & Maximum & Standard Deviation \\
\hline Diameter & $\mathrm{cm}$ & 34.07 & 20 & 50 & 7.87 \\
Length & $\mathrm{m}$ & 3.90 & 3 & 4 & 0.31 \\
Volume & $\mathrm{m}^{3}$ ccycle & 0.38 & 0.13 & 0.98 & 0.19 \\
\hline
\end{tabular}

Table 3. The basic statistical findings in loading

\begin{tabular}{lcccc}
\hline Phases & Average & Minimum & Maximum & Standard Deviation \\
\hline Loader moves to logs on the ground $(\mathrm{sec})$ & 9.77 & 6 & 14 & 2.05 \\
Loading the logs by the loader $(\mathrm{sec})$ & 5.50 & 4 & 8 & 1.14 \\
Loader moves to logging truck $(\mathrm{sec})$ & 9.97 & 5 & 15 & 2.76 \\
Loader Unloads logs the Truck $(\mathrm{sec})$ & 6.77 & 3 & 13 & 1.87 \\
Delay time $(\mathrm{sec})$ & 10.83 & 4 & 16 & 3.64 \\
Yield $\left(\mathrm{m}^{3} / \mathrm{h}\right)$ & 34.27 & 10.73 & 69.51 & 15.19 \\
\hline
\end{tabular}

In the loading operation with the loader, the average productivity was determined as $34.27 \mathrm{~m}^{3} /$ hour. In a similar study (Karaman, 1991), the average productivity in the operation of loading spruce logs with Liebher 902 loader was determined as $48.67 \mathrm{~m}^{3} /$ hour.

\subsection{Correlation Between Variables Affecting Productivity}

The Pearson Correlation Test was applied to determine the relationships between hourly productivity and variables (diameter, length, volume) (Table 4).
Correlation test results showed that there was a positive $(\mathrm{p}<0.001)$ relationship between $\log$ diameter and $\log$ volume and productivity at $99 \%$ confidence level. There was no significant relationship between log dimensions and productivity at $99 \%$ confidence level $(\mathrm{p}>0.5)$. This is due to the fact that the lengths of the log evaluated in the study are very close to each other. In similar studies in which the loader's productivity analysis was carried out, it was stated that $\log$ volume and log dimensions were effective factors on productivity (Javadpour, 2006; Kewilaa and Tehupeiory, 2015).

Table 4. Findings of correlation analysis

\begin{tabular}{lccccc}
\hline & & Diameter & Height & Volume & Productivity \\
\hline \multirow{3}{*}{$\begin{array}{l}\text { Pearson correlation } \\
\text { constant }\end{array}$} & Diameter & 1 & -0.083 & $.919^{* *}$ & $0.823^{* *}$ \\
& Height & -0.083 & 1 & 0.134 & 0.141 \\
& Volume & $0.919^{* *}$ & 0.134 & 1 & $0.851^{* *}$ \\
& Productivity & $0.823^{* *}$ & 0.141 & $0.851^{* *}$ & 1 \\
\hline \multirow{3}{*}{ Sig. (2-tailed) } & Diameter & & 0.662 & 0.000 & 0.000 \\
& Height & 0.662 & & 0.479 & 0.457 \\
& Volume & 0.000 & 0.479 & & 0.000 \\
\hline
\end{tabular}




\subsection{Regression Analysis Results}

Taking into account the correlation test results, Linear Regression Analysis was used to reveal the relationship between independent variables (diameter and volume) and dependent variable (productivity). The regression model was found to be significant at $99 \%$ confidence level $(\mathrm{p}<0.001)$ (Table 5). The obtained $\mathrm{R}^{2}$ value (0.74) showed that the regression model explained the loader efficiency sufficiently.

The regression model which includes the dependent variable ( $\mathrm{y}=$ productivity) and the independent variables $\left(\mathrm{x}_{1}=\right.$ diameter; $\mathrm{x}_{2}=$ volume $)$ representing the productivity is shown in the following equation:

$\mathrm{y}=-1.379+(0.509) \mathrm{x}_{1}+(47.731) \mathrm{x}_{2}$

The developed mathematical model showed that the most influential factor on productivity was the volume value. The graphs obtained as a result of regression analysis showed normal distribution (Figure 3, Figure 4).

Table 5. One-way ANOVA results

\begin{tabular}{llccccc}
\hline & Model & Sum of Squares & df & Mean Square & F & Sig. \\
\hline 1 & Regression & 4914.78 & 2 & 2457.39 & 37.38 & $0.000^{\mathrm{a}}$ \\
& Residual & 1775.02 & 27 & 65.74 & & \\
Total & 6689.80 & 29 & & & \\
\multicolumn{2}{l}{ a. independent variable: Diameter, Volume } \\
b. dependent variable: Yield
\end{tabular}

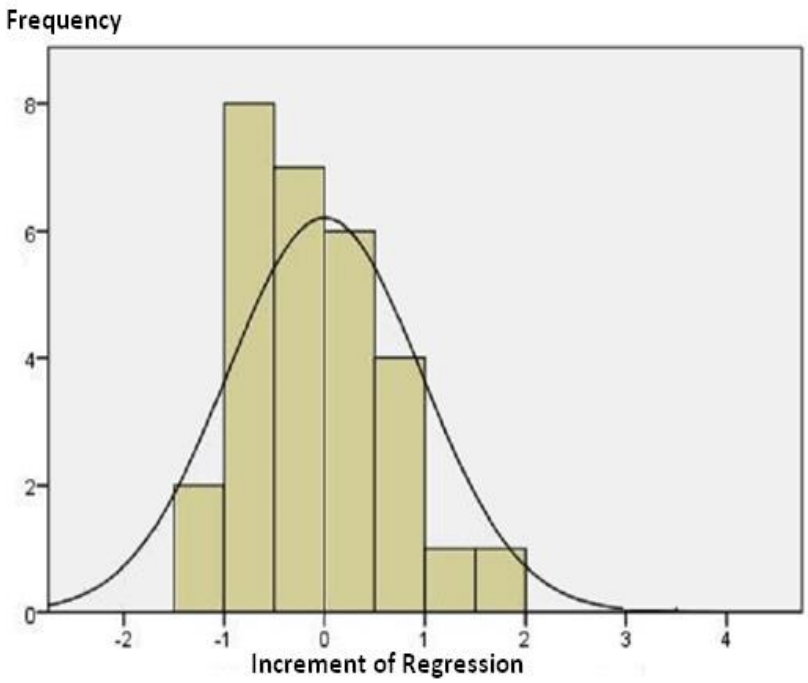

Figure 3. Regression histogram

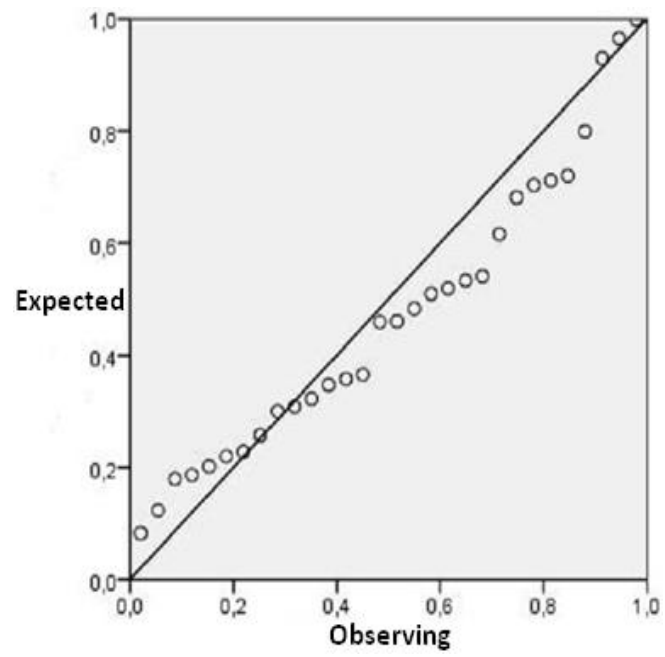

Figure 4. Normal probability graph

\subsection{Diameter Classes Results}

In order to examine the effect of measured product diameters on productivity, logs were divided into three diameter classes (small, medium, and large) according to the standard diameter classes of General Directorate of Forestry. Then, 0.05 significance level One-Way Analysis of Variance, using the relationship between the productivity of the diameter classes were evaluated (Table 6). According to the results obtained yield values increased from small diameter class, medium and large diameter class increased (Table 7). In a similar study, Naghdi (2005) stated that the increase in $\log$ dimensions increases the productivity in loading studies.

By using Tukey multiple comparison test, yield values of diameter classes were compared among themselves. According to the results, it was determined that yield values belonging to diameter classes showed significant differences at $95 \%$ confidence level $(\mathrm{p}<0.05)$ (Table 8).

Table 6. One-way ANOVA findings for diameter classes

\begin{tabular}{lccccc}
\hline & Sum of Squares & df & Mean Square & F & Sig. \\
\hline Between-group & 4225.01 & 2 & 2112.51 & 23.14 & 0.000 \\
Within-group & 2464.78 & 27 & 91.29 & & \\
Total & 6689.79 & 29 & & & \\
\hline
\end{tabular}


Akay et al.

Table 7. Basic statistical values for diameter classes

\begin{tabular}{lcccccc}
\hline $\begin{array}{l}\text { Diameter } \\
\text { Classes }\end{array}$ & $\mathrm{N}$ & Average & $\begin{array}{c}\text { Standard } \\
\text { Deviation }\end{array}$ & $\begin{array}{c}\text { Standard } \\
\text { Error }\end{array}$ & Minimum & Maximum \\
\hline Small & 8 & 16.43 & 4.95 & 1.75 & 10.73 & 25.23 \\
Medium & 14 & 36.35 & 9.82 & 2.62 & 22.79 & 63.70 \\
Large & 8 & 48.49 & 12.19 & 4.31 & 33.08 & 69.51 \\
Total & 30 & 34.27 & 15.19 & 2.77 & 10.73 & 69.51 \\
\hline
\end{tabular}

Table 8. Multiple comparison results for diameter classes

\begin{tabular}{ccccccc}
\hline $\begin{array}{c}\text { (I)Diameter } \\
\text { Classes }\end{array}$ & $\begin{array}{c}\text { (J) Diameter } \\
\text { Classes }\end{array}$ & Mean Difference (I-J) & $\begin{array}{c}\text { Standard } \\
\text { Error }\end{array}$ & Sig. & \multicolumn{2}{c}{ \%95 confidence level } \\
Lower limit & Upper limit \\
\hline \multirow{2}{*}{1} & 2 & $-19.92^{*}$ & 4.25 & 0.000 & -30.42 & -9.42 \\
& 3 & $-32.06^{*}$ & 4.78 & 0.000 & -43.91 & -20.22 \\
2 & 1 & $19.92^{*}$ & 4.24 & 0.000 & 9.42 & 30.42 \\
& 3 & $-12.14^{*}$ & 4.25 & 0.021 & -22.64 & -1.64 \\
3 & 1 & $32.06^{*}$ & 4.78 & 0.000 & 20.22 & 43.91 \\
& 2 & $12.14^{*}$ & 4.25 & 0.021 & 1.64 & 22.64 \\
\hline
\end{tabular}

\subsection{Volume Classes Results}

In order to investigate the effect of the measured product volumes on the productivity, the products were divided into three volume classes (low, medium and high). Then, 0.05 significance level of One-Way Analysis of Variance (One-Way ANOVA), using the relationship between the volume classes were evaluated (Table 9). According to the obtained results, productivity values increased from low volume class, medium and high volume class increased (Table 10). In a similar study in which Kewilaa and Tehupeiory
(2015) investigated the productivity and cost analysis of the grapple loader, a positive significant relationship was found between the average volume and weight of the products loaded in each cycle and the yield of the loading study. Tukey multiple comparison test was applied and the yield values of the volume classes were compared among themselves. According to the results, it was determined that the yield values of the volume classes formed showed a significant $(\mathrm{p}<0.05)$ differences at 95\% confidence level (Table 11).

Table 9. One-way ANOVA findings for volume classes

\begin{tabular}{lccccc}
\hline & Sum of & df & Mean Square & F & Sig. \\
\hline Between-group & 4494.94 & 2 & 2247.47 & 27.65 & 0.000 \\
Within-group & 2194.86 & 27 & 81.29 & & \\
Total & 6689.79 & 29 & & & \\
\hline
\end{tabular}

Table 10. Basic statistical values for volume classes

\begin{tabular}{ccccccc}
\hline Volume & $\mathrm{N}$ & Average & Standard & Standard & Minimum & Maximum \\
\hline Low & 11 & 19,45 & 6,94 & 2,09 & 10,73 & 31,79 \\
Medium & 12 & 38,28 & 9,27 & 2,65 & 29,30 & 63,70 \\
Hight & 7 & 50,69 & 11,33 & 4,28 & 33,49 & 69,51 \\
Total & 30 & 34,27 & 15,19 & 2,77 & 10,73 & 69,51 \\
\hline
\end{tabular}

Table 11. Multiple comparison results for volume classes

\begin{tabular}{|c|c|c|c|c|c|c|}
\hline \multirow{2}{*}{$\begin{array}{l}\text { (I) Volume } \\
\text { Classes }\end{array}$} & \multirow{2}{*}{$\begin{array}{l}\text { (J)Volume } \\
\text { Classes }\end{array}$} & \multirow{2}{*}{ Mean Difference (I-J) } & \multirow{2}{*}{$\begin{array}{l}\text { Standard } \\
\text { Error }\end{array}$} & \multirow{2}{*}{ Sig. } & \multicolumn{2}{|c|}{$\% 95$ confidence level } \\
\hline & & & & & Lower limit & Upper Limit \\
\hline \multirow{2}{*}{1} & 2 & $-18.83^{*}$ & 3.76 & 0.000 & -28.16 & -9.49 \\
\hline & 3 & $-31.24^{*}$ & 4.36 & 0.000 & -42.04 & -20.43 \\
\hline \multirow{2}{*}{2} & 1 & $18.83^{*}$ & 3.76 & 0.000 & 9.49 & 28.16 \\
\hline & 3 & $-12.41^{*}$ & 4.29 & 0.020 & -23.04 & -1.78 \\
\hline \multirow{2}{*}{3} & 1 & $31.24^{*}$ & 4.36 & 0.000 & 20.43 & 42.04 \\
\hline & 2 & $12.41^{*}$ & 4.29 & 0.020 & 1.78 & 23.04 \\
\hline
\end{tabular}




\section{Conclusions}

The loading operation has an important function to carry out the transportation of wood-based forest products smoothly. In this study, the grapple loader which is one of the most widely used mechanical production tools in the production of forest products has been analyzed in terms of productivity and the factors affecting the loader yield have been evaluated. When the average duration of the work stages in the loading study was examined, it was found that the most time consuming stage was the time of the loader moving to the truck (31.15\%), followed by the time of the loader moving back to the logs on the ground (30.52\%). In addition, it was found that lost time had a significant rate $(25.29 \%)$ in total working time.

According to the results, the average productivity was $34.27 \mathrm{~m}^{3} /$ hour. Correlation test results showed that there was a positive correlation $(\mathrm{p}<0.001)$ between $\log$ diameter and volume and productivity at $99 \%$ confidence level, whereas there was no significant relationship between log length and productivity. It was determined that the regression model developed for loader productivity and log diameter and volume was significant at $99 \%$ confidence level $(p<0.001)$ and explained loader productivity in sufficient level $\left(\mathrm{R}^{2}=\right.$ $0.74)$.

It was found that there was a significant relationship between diameter classes and productivity values and loader productivity increased from small diameter class to large diameter class. It was determined that productivity values of diameter classes showed significant $(\mathrm{p}<0.05)$ differences among themselves at 95\% confidence level. Likewise, there was a significant relationship between volume classes and productivity values and loader productivity from low volume class to high volume class. It was determined that yield values of the determined volume classes showed significant $(\mathrm{p}<0.05)$ differences among themselves at 95\% confidence level.

In order to carry out the production of forest products effectively, a good harmony between loading activity and felling, unloading, stacking and hauling is required. Therefore, the use of high-performance mechanical loaders in the loading will contribute to the success of the production of forest products. In Turkey, manual loading method based on manpower is still preferred in the loading of logs in some regions, especially in the loading of small size (paper and firewood) forest products. However, the lack of economic use of manpower in recent years and the problems experienced in hiring experienced workers indicate that loaders will be preferred more in loading works. Furthermore, the necessity of transporting wood-based products in a short time, in certain periods and sometimes in severe weather conditions makes it necessary for the use of loaders operating in high efficiency in all weather conditions.
Operator performance is also of key importance for using loaders with optimum efficiency. Therefore, the necessary theoretical and practical training should be given to loader operators. The results obtained from this study indicated that it will be appropriate to investigate the productivity of loaders in different sizes and capacities in loading various forest products (i.e. industry wood, mining pole, paper wood, etc.).

\section{References}

Acar, H.H., Senturk, N., 2000. Mechanization in wood production operations in mountainous forest area, Journal of Faculty of Forestry Istanbul University, Sery: B, (46):77-94.

Akay, A.E., Yuksel, A., Reis, M., Tutus, A., 2007. The impacts of ground-based logging equipment on forest soil, Polish Journal of Environmental Studies, 16(3):371-376.

Carus, S., 2002. Comparison of some volume formulas regarding the stem, segments and fractions of the stem, Suleyman Demirel University Faculty of Forestry Journal, Seri A, (1):101-114.

Coskun, K., Eroglu, H., Özkaya, M.S., Çetiner K., Bilgin, F., 2010. An assessment in terms of mechanization of timber harvesting operations in Artvin Forest Regional Directorate, 3. National Blacksea Forestry Congress, 20-22 May, Artvin.

Eker, M., Acar, H.H., 2006. Development of annual operational planning model for timber harvesting, Suleyman Demirel University, Institute of Science Journal, 10-2:235-248.

Eroglu, H., 2012. Effects of different logging techniques on forest soil compaction at mountainous terrain, Artvin Çoruh University Faculty of Forestry Journal, 13(2):213-225.

Javadpour, A., 2006. Productivity and cost analysis of skidding and loading in designed and roadside landing, Msc Thesis, Guilan University, Iran, 85 p.

Karaman, A., 1991. Investigating time, productivity, and cost of Liebher 902 during loading and piling of logs in forest depots. Msc Thesis, Trabzon. $103 \mathrm{p}$.

Kewilaa, B., Tehupeiory, A., 2015. Effects of working time and the volume and weight of timber on productivity of log loader caterpillar type $966 \mathrm{~F}$ and WL 980C. Wood Research Journal, 6(1):8-13.

Kovácsová, P., Antalová, M., 2010. Precision forestry - definition and technologies. Journal of Forestry Society of Croatia, 134(11-12):603-611.

Naghdi. R., 2005. Investigation and comparison of two harvesting systems: tree length and cut-tolength method in order to optimize road network planning in Neka, Iran. PhD Thesis, Tarbiat Modares University Tehran, $177 \mathrm{p}$. 